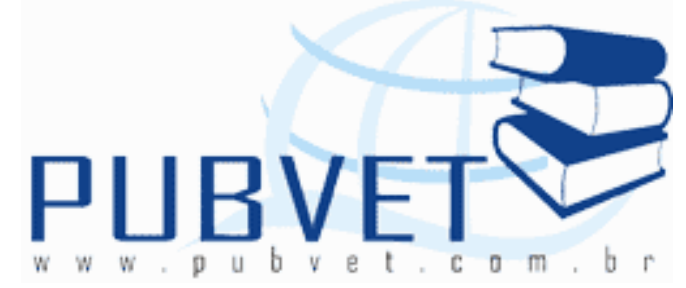

PUBVET, Publicações em Medicina Veterinária e Zootecnia.

\title{
Prevalência de lesões sugestivas de brucelose em bovinos abatidos no Estado do Pará, Brasil
}

Alexandre Moura Chagas ${ }^{1}$; Peter Bitencourt Faria ${ }^{2}$; Geraldo Marcio da Costa ${ }^{2}$

${ }^{1}$ Médico Veterinário da Agência de Defesa Agropecuária do Estado do Pará, Pará, Brasil

${ }^{2}$ Professor da Universidade Federal de Lavras, Departamento de Medicina Veterinária, Caixa Postal 3037, CEP 37200-000, Lavras-MG, Brasil. E-mail: peterbfvet@yahoo.com.br

\section{Resumo}

A brucelose é uma enfermidade infecto-contagiosa provocada por bactérias do gênero Brucella, que infectam animais e o homem, causando graves perdas econômicas, além de suscitar preocupação com a saúde pública. As suas principais manifestações nos animais são abortos, nascimentos prematuros, esterilidade e baixa produção de leite. O presente estudo objetivou identificar a prevalência de lesões sugestivas da ocorrência de brucelose em carcaças condenadas de animais da espécie bovina, originados de vários municípios do Estado do Pará e abatidos em seis estabelecimentos registrados no Serviço de Inspeção Estadual (SIE). Os dados foram obtidos através da revisão dos relatórios com o registro das inspeções diárias realizadas por Médico Veterinário, a partir das informações arquivadas no Serviço de Inspeção Estadual. Foram estudados, os dados de 295.085 bovinos abatidos, sendo 
56.740 machos e 238.345 fêmeas, no período de janeiro a dezembro de 2008 . Verificou-se um total de 879 bovinos condenados por lesões sugestivas de brucelose, onde a principal lesão encontrada foi a ocorrência de bursite cervical, apresentando uma prevalência de $0,3 \%$. Dentre os bovinos diagnosticados com brucelose e condenados, observou-se uma prevalência de 0,35\% nas fêmeas e de 0,08\% nos machos abatidos. Desta forma, houve um predomínio na condenação das fêmeas $(94,65 \%)$ em relação aos machos $(5,35 \%)$. A presença dessas lesões, sugerem que a brucelose continua difundida nos rebanhos desta região, necessitando estabelecer medidas de controle e profilaxia incluídas no Programa Nacional de Controle e Erradicação da brucelose e tuberculose (PNECBT) no Estado do Pará.

Palavras-chave: Saúde pública, epidemiologia, condenação de carcaças

\section{Prevalence of lesions suggestive of brucellosis in cattle slaughtered in the state of Pará, Brazil}

\section{Abstract}

Brucellosis is an infectious disease caused by bacteria of the genus Brucella, which infect animals and humans, causing serious economic losses, besides raising concerns about public health. Its main manifestations in animals are abortion, premature births, sterility and low milk production. This study aimed to identify the prevalence of lesions suggestive of the occurrence of brucellosis in animals condemned for bovine animals originated from various country of Pará and slaughtered in six establishments registered with the State Inspection Service (SIE). Data were collected by review of reports with records of daily inspections performed by the veterinarian, from the information filed in the State Inspection Service. We studied the data of 295,085 cattle killed, with 56,740 males and 238,345 females in the period January to December 2008. There are a total of 879 cattle condemned for lesions suggestive of brucellosis, where the primary lesion was found the occurrence of cervical bursitis, with a prevalence of $0.3 \%$. Among those diagnosed with bovine brucellosis and 
convicted, there was a prevalence of $0.35 \%$ in females and $0.08 \%$ in barrows slaughtered. Thus, there was a predominance in the condemnation of the females (94.65\%) compared to males (5.35\%). The presence of these lesions suggest that brucellosis in sheep remains widespread in this region, need to establish control and preventive measures included in the National Control and Eradication of brucellosis and tuberculosis (PNECBT) in Para.

Keywords: Public health, epidemiology, condemnation of carcasses

\section{Introdução}

A Brucelose representa um grave problema de saúde pública, sobretudo pelo caráter ocupacional por causa da manipulação de carcaças contaminadas em matadouros e propriedades rurais por profissionais afins, pela ingestão de alimentos crus contaminados ou ainda, por acidentes vacinais e laboratoriais. Acomete principalmente assistentes agropecuários, médicos veterinários, tratadores, vaqueiros, laboratoristas e magarefes, por desenvolverem atividades que os expõem ao risco de infecção com maior freqüência (FREITAS et al., 2001; MONTEIRO et al., 2006).

O conhecimento sobre as patologias encontradas em bovinos abatidos em uma determinada região e que causam prejuízos aos criadores é de grande valia para detectar pontos negativos da cadeia passíveis de modificações. A identificação dessas patologias permite a elaboração e adoção de medidas preventiva, combate e erradicação, inclusive de orientação a produtores e políticas públicas que visem à prevenção de zoonoses.

No Brasil, a brucelose animal ocorre de forma endêmica em todas as regiões, com prevalências variáveis levantadas nos inquéritos epidemiológicos e nos diagnósticos, que demonstram índices de 2,5\% a 18\% (FREITAS \& OLIVEIRA, 2005).

O último diagnóstico da situação nacional da brucelose bovina foi realizado em 1975 e apontava a seguinte situação: 4\% de soropositividade na Região Sul, 7,5\% na Região Sudeste, 6,8\% na Região Centro-Oeste, 2,5\% na Região Nordeste e $4,1 \%$ na Região Norte. De acordo com dados oficiais a 
prevalência de animais reagentes de 1988 a 1998 se manteve entre 4\% a 5\%. Atualmente a brucelose continua disseminada por todo o território nacional, porém, a sua prevalência e distribuição regional não estão bem caracterizadas (BRASIL, 2006). Tendo com isso a necessidade de ser conhecer a prevalência e características epidemiológicas de cada região para que se possa fornecer subsídios e direcionamento aos programas de controle (FREITAS et al, 2008).

Os estudos sobre bursite não são numerosos, notadamente, os que se referem a bovinos e, ainda, em menor número, os que tratam da bursite cervical. Deve-se destacar que a grande maioria desses trabalhos refere-se a relatos de casos objetivando o isolamento do agente brucélico dos higromas, ou a realização de exames sorológicos para brucelose, apenas nos animais com a patologia. Em alguns desses trabalhos, conseguiu-se isolar 0 agente brucélico ou comprovou-se a sorologia positiva de animais com bursite, reconhecendo-se o envolvimento da Brucella sp. nessa patologia (ALMEIDA et al., 2000).

O objetivo deste estudo foi identificar a prevalência da brucelose em carcaças condenadas de animais da espécie bovina, originados de vários municípios do Estado do Pará, registrados no Serviço de Inspeção Estadual.

\section{Material e Métodos}

O presente trabalho foi realizado no período de janeiro a dezembro de 2008, no Estado do Pará, em seis estabelecimentos de abate de bovídeos localizados nos municípios de Altamira, Barcarena, Belém, Castanhal e Santa Izabel, todos registrados no Serviço de Inspeção Estadual - SIE/PA da Agência de Defesa Agropecuária do Estado do Pará - ADEPARÁ.

Os dados totais de condenação de carcaças de bovinos pela brucelose e o número total de animais abatidos foram obtidos mensalmente durante o ano de 2008, através da revisão dos relatórios com o registro das inspeções diárias realizadas por Médico Veterinário, a partir das informações arquivadas no 
Serviço de Inspeção Estadual - SIE/PA, pertencentes a cada um desses estabelecimentos registrados.

Os Médicos Veterinários responsáveis pela inspeção dos animais nesses estabelecimentos realizavam seus diagnósticos da brucelose e conseqüentemente de condenação das carcaças de bovinos, após criterioso exame macroscópico dos mesmos. A indicação para condenação por brucelose foi realizada considerando a presença da bursite cervical, realizada durante a inspeção das carcaças. O procedimento foi realizado através da inspeção rotineira e sistemática, dos ligamentos cervicais, em cada animal abatido, com incisões entre a terceira e a quarta vértebras torácicas para melhor exposição desses ligamentos.

\section{Resultados e Discussão}

Os animais abatidos eram originados de vários municípios do Estado do Pará, incluindo os do Arquipélago do Marajó, o qual possui históricos de grande número de animais afetados pela brucelose. Foram estudados dados referentes a 295.085 bovinos abatidos no estabelecimento registrado no SIE/PA, no período de janeiro a dezembro de 2008, sendo destes 56.740 machos e 238.345 fêmeas.

Através do levantamento dos registros de ocorrência, foi realizada a apresentação dos dados de ocorrência e prevalência de acordo com os meses e por sexo, sem aplicação de teste estatístico.

Os 295.085 bovinos procedentes de vários municípios do Estado do Pará abatidos em seis estabelecimentos de abate sob inspeção do Serviço de Inspeção Estadual - SIE/PA no período de janeiro a dezembro de 2008, foram diagnosticados e condenados por Médicos Veterinários um total de 879 carcaças por brucelose, apresentando uma prevalência de 0,3\% (879/295.085), Tabela 01. 
Tabela 1. Ocorrência de lesões sugestivas de brucelose em bovinos abatidos em seis estabelecimentos com registro no Serviço de Inspeção Estadual SIE/PA.

\begin{tabular}{ccc}
\hline Ano 2008 & $\begin{array}{c}\text { Número de bovinos } \\
\text { condenados }\end{array}$ & $\begin{array}{c}\text { Número total de } \\
\text { bovinos abatidos }\end{array}$ \\
\hline Mês & 112 & 25.537 \\
Fevereiro & 94 & 22.771 \\
Março & 76 & 23.330 \\
Abril & 87 & 24.526 \\
Maio & 71 & 26.540 \\
Junho & 65 & 24.844 \\
Julho & 44 & 24.513 \\
Agosto & 61 & 22.759 \\
Setembro & 53 & 24.431 \\
Outubro & 54 & 26.095 \\
Novembro & 82 & 24.508 \\
Dezembro & $\mathbf{8 7 9}$ & 25.231 \\
\hline Total & & $\mathbf{2 9 5 . 0 8 5}$ \\
\hline & 50 & \\
\hline & 54 & \\
\hline
\end{tabular}

Fonte: Dados da Agência de Defesa Agropecuária do Estado do Pará - Serviço de Inspeção do Estado - SIE/PA, período de janeiro a dezembro de 2008.

Este percentual é considerado preocupante, uma vez que a enfermidade ocasiona transtornos reprodutivos e conseqüentes perdas econômicas, além de representar riscos à saúde pública. Tal situação pode ter sido originada em 
virtude da não vacinação, da aquisição de animais sem os exames, a demora ou não eliminação de animais com brucelose na propriedade e, de precárias condições sanitárias no manejo dos animais.

De acordo com ALMEIDA et al. (2000) entre os agentes sépticos, responsabilizados pela etiologia das bursites, estão as brucelas, devido à afinidade peculiar por bolsas mucosas. No trabalho de FREITAS \& OLIVEIRA (2005), o diagnóstico sorológico demonstrou a ocorrência de infecção brucélica em bovinos e bubalinos abatidos portadores de bursite, sugerindo a ocorrência de infecção por Brucella spp. em bovídeos. Segundo estes autores, essas lesões inflamatórias de origem hematogênica denominadas bursites, caracterizadas como bolsas serosas localizadas na região da cruz, adjacentes à porção funicular do ligamento cervical e apófises espinhosas cervicais, têm sido isoladas brucelas e detectados títulos de anticorpo aglutinante compatíveis com brucelose.

As lesões articulares, bursites assim como lesões na glândula mamária podem ser observadas em casos crônicos da doença (LAGE et al., 2008).

No exame post mortem, realizado nos frigoríficos por inspetores do Serviço de Inspeção Municipal (SIM), Estadual (SIE) e Federal (SIF) que as bursites podem ser diagnosticadas mediante exames macroscópicos (ALMEIDA et al., 2000).

Na Figura 01, são apresentados os índices de prevalência dos animais abatidos e condenados nos meses de janeiro a dezembro do ano de 2008 por lesões sugestivas de brucelose.

Em trabalho realizado por LOPES (2008) a prevalência da brucelose bovina encontrada foi de $0,19 \%$, sendo superior a prevalência encontrada no trabalho de FREITAS \& OLIVEIRA (2005) de 0,099\%, no entanto, o presente trabalho apresentou prevalência de $0,30 \%$. No levantamento da prevalência das condenações por lesões sugestivas de brucelose em matadouro sob inspeção municipal, ALVIM et al (2007), no período entre outubro de 2003 e maio de 2004 , encontraram resultado de $0,82 \%$ para um abate total de 8.277 bovinos. 


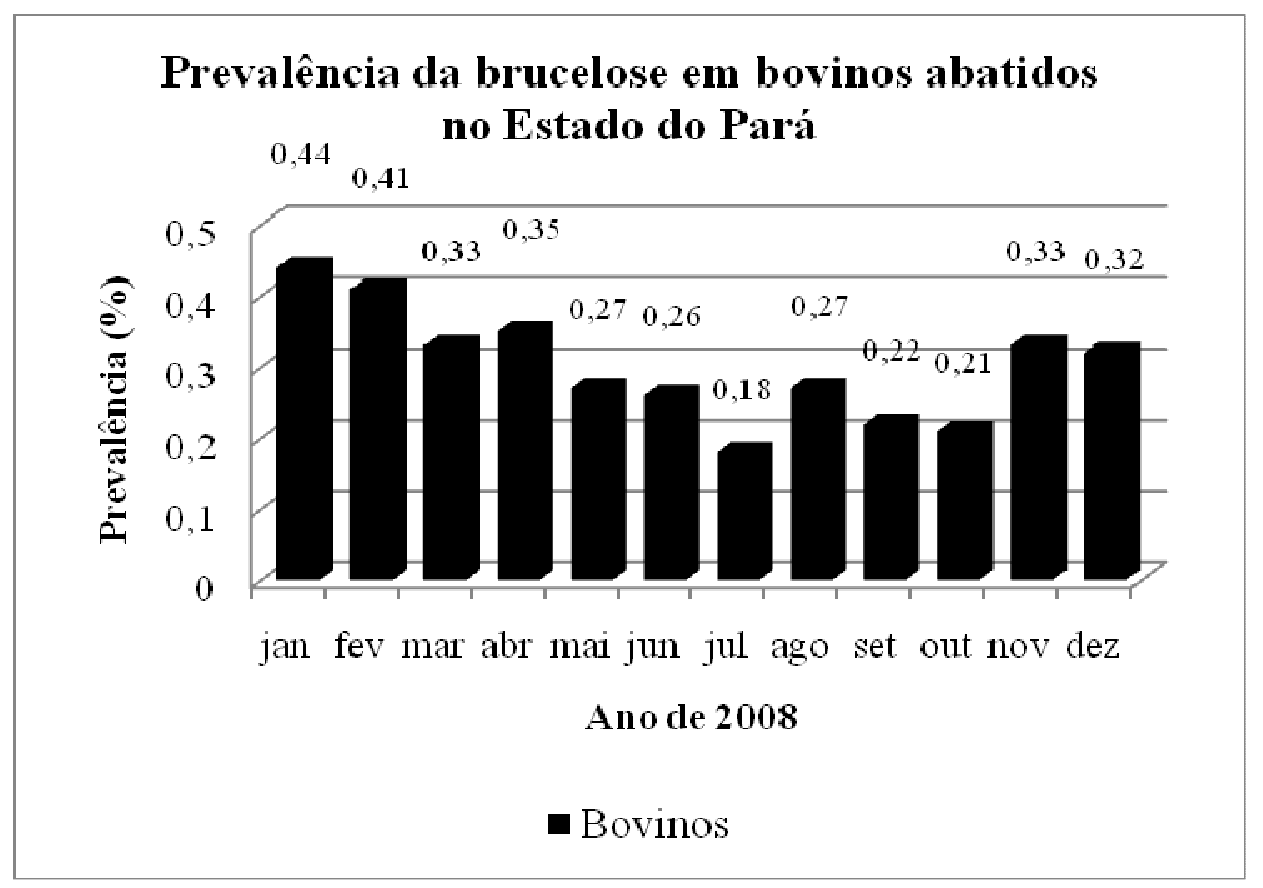

Figura 1. Prevalência da brucelose em bovinos abatidos no Estado do Pará, no período de janeiro a dezembro de 2008.

Na Tabela 2, pode-se observar uma diferença entre os sexos na prevalência da brucelose nos bovinos abatidos, demonstrando prevalência de 0,35\% para as fêmeas e 0,08\% para os machos. FREITAS et al. (2008), observou em seu trabalho que dentre os animais positivos, as fêmeas foram mais afetadas, apresentando $82,2 \%$, quando comparadas com os machos que foram $18,5 \%$. Sua possível explicação reside no fato de um macho cobrir várias fêmeas, e quando este estiver positivo, a chance de propagação para as fêmeas é bem maior, sendo a brucelose uma enfermidade sexualmente transmissível. No entanto, apesar de a brucelose ser sexualmente transmissível, a melhor explicação é o fato da existência de muitas fêmeas no rebanho das propriedades rurais, onde possuem o mesmo manejo. Com isso a presença do aborto, que representa uma importante fonte de infecção para os animais, principalmente para fêmeas, podendo se infectar por contato com fetos abortados, envoltórios fetais e descargas vaginais. 
Tabela 2. Ocorrência da brucelose nos bovinos abatidos em seis estabelecimentos com registro no Serviço de Inspeção Estadual SIE/PA, de acordo com o sexo.

\begin{tabular}{|c|c|c|c|c|}
\hline \multirow[t]{2}{*}{ Mês/2008 } & \multicolumn{2}{|c|}{$\begin{array}{c}\text { Número de bovinos } \\
\text { condenados }\end{array}$} & \multicolumn{2}{|c|}{$\begin{array}{l}\text { Número total de bovinos } \\
\text { abatidos }\end{array}$} \\
\hline & Macho & Fêmea & Macho & Fêmea \\
\hline Janeiro & 01 & 111 & 5.138 & 20.399 \\
\hline Fevereiro & 01 & 93 & 4.372 & 18.399 \\
\hline Março & 05 & 71 & 3.963 & 19.367 \\
\hline Abril & 05 & 82 & 4.587 & 19.939 \\
\hline Maio & 04 & 67 & 4.664 & 21.876 \\
\hline Junho & 03 & 62 & 3.501 & 21.343 \\
\hline Julho & 01 & 43 & 3.805 & 20.708 \\
\hline Agosto & 02 & 59 & 3.918 & 18.841 \\
\hline Setembro & 04 & 49 & 4.596 & 19.835 \\
\hline Outubro & 10 & 44 & 6.897 & 19.198 \\
\hline Novembro & 08 & 74 & 5.009 & 19.499 \\
\hline Dezembro & 03 & 77 & 6.290 & 18.941 \\
\hline Total & 47 & 832 & 56.740 & 238.345 \\
\hline
\end{tabular}

Fonte: Dados da Agência de Defesa Agropecuária do Estado do Pará - Serviço de Inspeção do Estado - SIE/PA, período de janeiro a dezembro de 2008.

Conforme os dados da Tabela 2, a condenação de bovinos abatidos pela brucelose foi maior nas fêmeas com relação aos machos, sendo sua 
prevalência com relação ao sexo, demonstrada na Figura 2. Em geral, em relação ao total de carcaças condenadas por lesões sugestivas de brucelose, foi encontrado um percentual de 5,35\% em machos e de $94,65 \%$ em fêmeas.

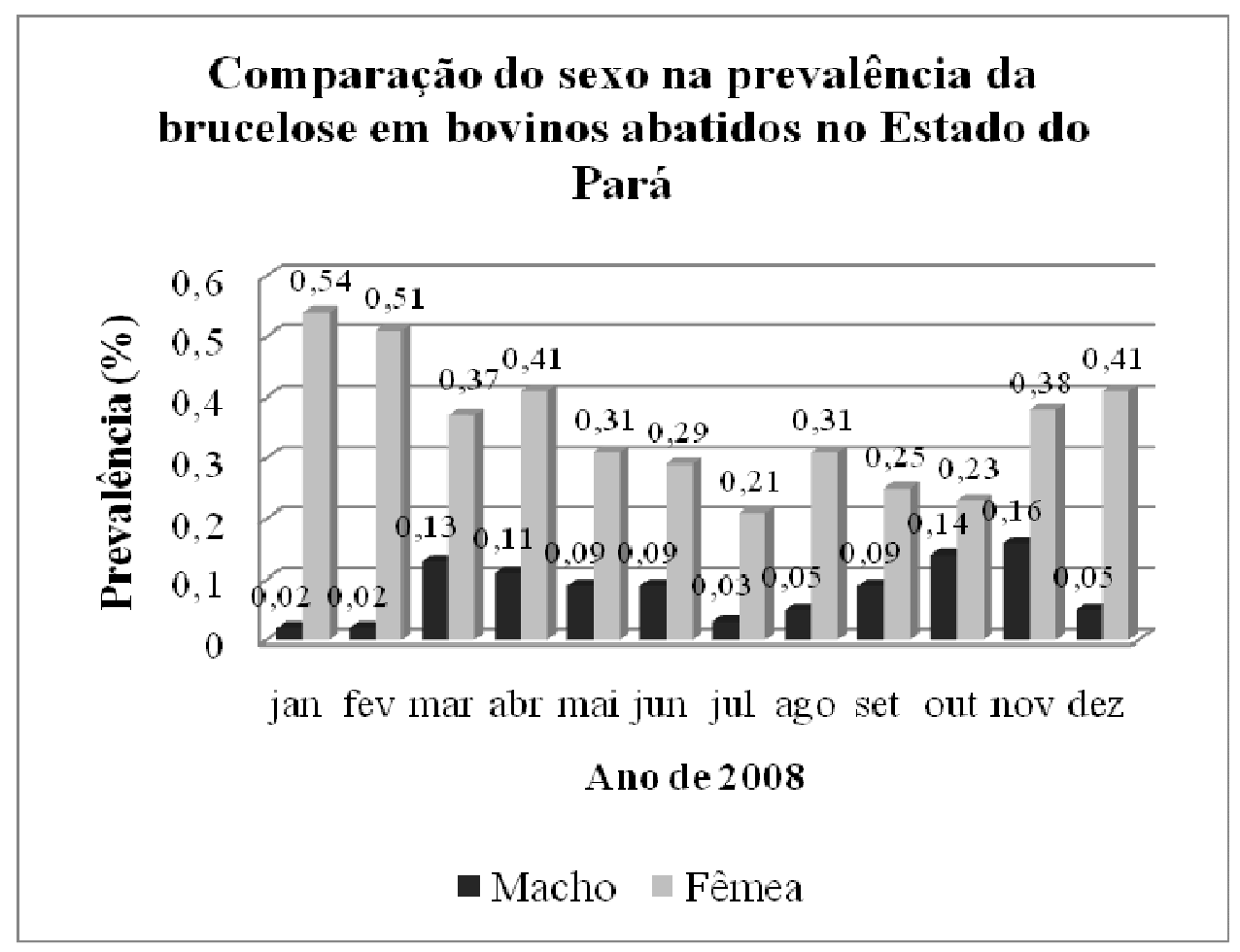

Figura 2. Comparação do sexo na prevalência da brucelose em bovinos abatidos no Estado do Pará, no período de janeiro a dezembro de 2008.

SANTOS et al. (2007) descreveram no seu trabalho como sendo estatisticamente significativa a associação entre a susceptibilidade e sexo, obtendo uma prevalência de $9,91 \%$ (23/232) na fêmeas, enquanto que nos machos foi de $1,07 \%$ (2/187), de um total de 419 bovinos amostrados, $55,36 \%$ eram fêmeas e $44,63 \%$ em machos.

No trabalho realizado por FREITAS \& OLIVEIRA (2005), estes citaram que embora os animais com brucelose não tenha sido observado correlação entre o sexo, espécie a distribuição de frequência de infecção nos bovídeos abatidos em Belém-PA, maior foi a ocorrência nas fêmeas das duas espécies. 
OGATA et al. (2009) realizando um estudo para caracterizar a situação epidemiológica da brucelose bovina no Estado do Tocantins, entre fevereiro de 2002 e agosto de 2003, encontraram um total de 4,4\% fêmeas bovinas adultas positivas. RIBEIRO et al. (2003) por outro lado, no município de Ilhéus-BA, encontraram uma prevalência de 1,9\% para um total de 916 animais testados para ocorrência de brucelose. Os resultados desses autores indicam que a brucelose é uma doença prevalente no rebanho brasileiro independente do estado.

Apesar dos casos de brucelose encontrada nestes estabelecimentos, a sua prevalência poderá ser reduzida, buscando futuramente a sua erradicação, mas para isso é preciso uma atuação ativa, série e em conjunta dos órgãos envolvidos no setor agropecuário, principalmente o órgão responsável pela Defesa e Inspeção Agropecuária do Estado.

Para a brucelose bovina, as estratégias de combate são bastante conhecidas e podem ser resumida em vacinação, certificação de propriedades livres por rotinas de testes indiretos, controle da movimentação de animais e sistema de vigilância específico (POESTER et al., 2009). Desta forma a busca pela erradicação ocorrência da brucelose nos animais, parte desde a sua criação nas propriedades rurais, com a implantação das medidas de controle e profilaxia incluídas no PNECBT. Tendo o cuidado de realizar trabalhos de educação sanitária sobre a doença, conscientizando a população envolvida direta ou indiretamente com a criação de animais.

Essa preocupação em reduzir a disseminação da brucelose, deve-se a importância da doença, pois é responsável por grandes perdas econômicas na agropecuária e devida ser considerada uma zoonose, causando grave problema na saúde pública, daí a importância da presença de Médicos Veterinários nos estabelecimentos para a inspeção das carcaças, garantido alimentos seguros para o consumo da população. 
CHAGAS, A.M., FARIA, P.B. e COSTA, G.M. Prevalência de lesões sugestivas de brucelose em bovinos abatidos no Estado do Pará, Brasil. PUBVET, Londrina, V. 7, N. 24, Ed. 247, Art. 1632, Dezembro, 2013.

\section{Conclusão}

A prevalência da brucelose nas carcaças dos bovinos abatidos nos estabelecimentos com serviço de inspeção do Estado do Pará mostra que a brucelose continua difundida nos rebanhos desta região, apresentando-se de forma preocupante. Não sendo, no entanto, nenhuma surpresa visto que todo o território nacional ainda encontra-se endêmica para a doença em questão, com maior prevalência da brucelose nas carcaças das fêmeas da espécie bovina.

\section{Referências Bibliográficas}

ALMEIDA, L.P.; REIS, D.O.; GERMANO, P.M.L. Brucelose em bovinos com bursite cervical diagnosticada em abatedouro sob inspeção federal. Ciência Rural, v.30, n.2, p.287-291, 2000.

ALVIM, N.C.; BERMEJO, V.J.; PINHEIRO JÚNIOR, O.A.; FILADELPHO, A.L. Incidência e destino de carcaças de bovinos acometidos por brucelose e tuberculose no município de São Félix do Xingu-PA no período de outubro de 2003 a maio de 2004. Revista Científica Eletrônica De Medicina Veterinária, periodicidade semestral, ano IV, n. 8, jan. 2007.

BRASIL, Ministério da Agricultura, Pecuária e Abastecimento. Secretaria de Defesa Agropecuária - Departamento de Saúde Animal, 2006. Programa Nacional de Controle e Erradicação da Brucelose e Tuberculose (PNCEBT) - Manual Técnico. Brasília: MAPA/DAS/DSA, 2006, 188p.

FREITAS, F.A.D.; CAVALCANTI, M.L.; MARQUES, A.S.C.; MESQUITA, F.P.N.; AMORIM, A.S.; LEITE, A.I. Prevalência de brucelose em bovinos na região do Potengi, estado do Rio Grande do Norte. Acta Veterinária Brasílica, v. 2, n. 4, p. 118-122, 2008.

FREITAS, J.A.; GALINDO, G.A.R.; SANTOS, E.J.C.; SARRAF, K.A.; OLIVEIRA, J.P. Risco de brucelose zoonótica associado a suínos de abate clandestino. Revista de Saúde Pública, $V$. 35, n. 1, p. 101-102, 2001.

FREITAS, J.A.; OLIVEIRA, J.P. Pesquisa de infecção brucélica em bovídeos abatidos portadores de bursite. Arquivos do Instituto Biológico, v. 72, n. 4, p. 427-433, 2005.

LAGE, A.P.; POESTER, F.P.; PAIXÃO, T.A.; SILVA, T.M.A.; XAVIER, M.N.; MINHARRO, S.; MIRANDA, K.L.; ALVES, C.M.; MOL, J.P.S.; SANTOS, R.L. Brucelose bovina: uma atualização. Revista Brasileira de Reprodução Animal, v. 32, n. 3, p. 202-212, 2008.

LOPES, C. A. R. Prevalência de brucelose e tuberculose em bovinos abatidos sob inspeção estadual no município de Aracruz - Espírito Santo. 2008. 34p. Monografia (Especialização em higiene e inspeção de produtos de origem animal) - Universidade Castelo Branco, Rio de janeiro.

Disponível em: <http://www.qualittas.com.br/documentos/Prevalencia $\% 20$ de $\% 20$ Brucelose $\% 20$ e $\% 20 T u b$ erculose $\% 20$ em $\% 20$ Bovinos $\% 20-\% 20$ Camila\%20Alvarez $\% 20$ Rocha\%20Lopes.PDF> Acesso em 28 de abril de2010. 
MONTEIRO, L.A.R.C.; PELLEGRIN, A.O.; ISHIKAWA, M.M.; OSORIO, A.L.A.R.. Investigação epidemiológica da brucelose bovina em um estrato do Estado de Mato Grosso do Sul. Pesquisa Veterinária Brasileira, v.26, n.4, pp. 217-222, 2006.

OGATA, R.A.; GONÇALVES, V.S.P.; FIGUEIREDO, V.C.F.; LÔBO, J.R.; RODRIGUES, A.L.; AMAKU, M.; FERREIRA, F.; FERREIRA NETO, J.S.; DIAS, R.A. Situação epidemiológica da brucelose bovina no Estado do Tocantins. Arquivo Brasileiro de Medicina Veterinária e Zootecnia, v. 61, supl. 1, p. 126-134, 2009.

POESTER, F.; FIGUEIREDO, V.C.F.; LÔBO, J.R.; GONÇALVES, V.S.P.; LAGE, A.P.; ROXO, E.; MOTA, P.M.P.C.; MÜLLER, E.E.; FERREIRA NETO, J.S. Estudos de prevalência da brucelose bovina no âmbito do Programa Nacional de Controle e Erradicação de Brucelose e Tuberculose: introdução. Arquivo Brasileiro de Medicina Veterinária e Zootecnia, v. 61 , supl. 1, p. 1-5, 2009.

RIBEIRO, A.R.P.; LOBATTO, F.C.F.; ABREU, V.L.V.; FARIA, E.S.; SILVA, J.A. Prevalência de tuberculose e brucelose bovina no município de Ilhéus. Arquivo Brasileiro de Medicina Veterinária e Zootecnia, v. 55, n. 1, p. 120-122, 2003.

SANTOS, H.P.; TEIXEIRA, W.C.; OLIVEIRA, M.M.M.; PEREIRA, H.M.; OLIVEIRA, R.A.; NEGREIROS, R.C.; SOARES FILHO, P.M.; SANTANA, S.S.; CASTRO, R.S. Brucelose bovina e humana diagnosticada em matadouro municipal de São Luís - MA, Brasil. Ciência Veterinária nos Trópicos, v. 10, n. 2/3, p. 86-94, 2007. 